no hace otra cosa, que seguir las indicaciones de su maestro Vives en lo concerniente a los actos que deben presidir la vida de un buen cristiano y entre los que destaca ayudar a los pobres. Del mismo modo Enrique III de Nassau había fundado en Breda en 1532 una dotación para los pobres, en 1535 un lugar para huérfanos y en 1536 una institución para recoger ayudas y distribuirlas entre los necesitados ${ }^{29}$. Además, en su testamento, dejó algunas sumas para los «pobres vergonzantes» de sus tierras ${ }^{30}$.

Otro dato curioso del susodicho libro es que fue expurgado conforme al índice expurgatorio de 1612, tal como se lee en las guardas. Este índice seguía al redactado en 1583 por el Padre Juan de Mariana y otros teólogos según las órdenes del Cardenal Gaspar Quiroga, donde se decía que en los libros de horas había de suprimirse todo lo que tuviera relación con promesas y esperanzas vanas y temerarias o fuera afín a prácticas supersticiosas ${ }^{31}$. En el libro de Doña Mencía se ha tachado todo un párrafo en el folio $34 \mathrm{v}$.: «Scio enim quod in quacumque die tuarum passionarum memoriam habuero, salvus ero" (Se en efecto que en cualquier momento en que me acuerde de tu pasión, me salvaré).

La iluminación del libro se hizo en el taller de Simón Bening. Ya hemos mencionado que, entre 1539 y 1540 , se le había encargado a este maestro decorar unos libros de horas para la Marquesa del Zenete, alguno de ellos podría ser el que venimos describiendo. Pero si comparamos sus miniaturas con las que realizó Bening en otros manuscritos ${ }^{32}$, las nuestras parecen obra de taller y no del propio maestro. Simón Bening, conocido en su época como Simón de Brujas (1483-1561), fue uno de los mejores y más conocidos iluminadores flamencos del siglo Xvi. Heredó de su padre, Alejandro Bening, el taller y el control del mercado flamenco para la elaboración de libros de rezo. En 1508 se registró como maestro individual, asumiendo todo el control en 1519, cuando murió su padre ${ }^{33}$.

Por último diremos que, gracias a la conservación de este ejemplar en el Instituto Valencia de Don Juan, podemos conocer, al menos, como era uno de los 12 libros de horas que poseía la Marquesa del Zenete en el momento de su fallecimiento.

Juana Hidalgo Ogayar Universidad de Alcalá

\title{
UN PROYECTO INÉDITO DEL ARQUITECTO JUAN GÓMEZ DE MORA (1586-1648)
}

La ciudad en la que el colectivo desarrolla su actividad, bajo el punto de vista de su estructura urbano-arquitectónica, no vino a ser en España en el siglo xVII una suma de ideas creativas individuales, sino más bien una realidad que articuló lo particular en un proyecto común, con el que se supo emitir una categoría de dictámen caracterizado y definido como el fruto de unas voluntades o de unas conductas solidarias. En la Edad Moderna, a nivel nacional, las crisis econó-

\footnotetext{
29 Steppe, J. K., Mencia de Mendoza et ses relations..., p. 486.

30 Archivo del Palau, Marquesado del Zenete, leg. 124 y Steppe, J. K., Mencia de Mendoza et ses relations..., p. 486.

31 Sierra Corella, A., La censura de libros y papeles en España. Indices y catálogos de los prohibidos y expurgados, Madrid, 1947.

32 Weale, J., "Simon Binninck miniaturist», The Burlington Magazine, VIII, 1906, p. 335. Destree, J., Les Heures de Notre-Dame dites de Hennessy, Bruselas, 1923, pp. 5 y 12-13. Testa, J. A., Rosarium (Ms. Western 99, Biblioteca Chester Beatty de Dublín) reproducción y estudio del manuscrito, ed. Casariego S. A., Madrid, 1987.

33 Durrieu, P., "Alexandre Bening et les peintres de bréviaire Grimani", Gazette des Beaux Arts, V, 1891, pp. 345-364 y VI, 1891, pp. 55-69. Loo, Hulin de, "La vignette chez les enlumineurs gantois entre 1470 et 1500 ", Académie Royale de Belgique, Bulletin de la classe des Beaux-Arts, XXI, 1939, pp. 168-179. Hidalgo Ogayar, J., "Libro de horas de William Hastings», Goya, n. ${ }^{\circ}$ 177, Madrid, 1983, pp. 127-131.
} 
micas sorprendieron a las autoridades municipales y estatales en el mismo grado de imprevisión que en épocas anteriores, y no dejaron de ser graves y especialmente funestas sus consecuencias para el mundo de las artes en general y especialmente para el campo de lo arquitectónico o urbanístico que implica costos económicos de gran alcance. Fue tal vez esta circunstancia la que motiva que arquitectos y urbanistas cortesanos del siglo xvII se refugien en planteamientos de diseño simplificado y escueto, se esfuercen en manifestar un gran interés por la planta regular, por el uso reiterativo del cubo y el cuadrado, por los recursos de los ángulos rectos como medio para componer el dispositivo conceptual de los edificios, o la sistemática permanencia en las líneas horizontales o piramidales.

La casi totalidad de las casas que se construyen en Madrid en el siglo xvII, incluso las que se someten a una remodelación para ser modernizadas, se desarrollan bajo un método de concepción arquitectónica de gran simplicidad, adaptándose a la escasez de medios económicos de la época. En los diseños se mantiene un tipo de composición lineal, cuyo volumen alberga entre dos y cinco cuerpos y cuyos muros quedan retranqueados respecto a los antepechos del corrido balconaje. Las ventanas, como sistema de iluminación, en su proporcionado tamaño son espacios abiertos que ofrecen brillantes efectos de luz y sombra en las superficies murales. La amplitud del ventanaje es sin duda el adecuado para disfrutar tanto de las vistas de la calle como para facilitar la ventilación necesaria estival. El vano se convierte en un recurso expresivo, en un motivo arquitectónico en si mismo, elaborado a partir de un estudio detallado del control del medio ambiente doméstico, externo e interno.

El diseño que hoy damos a conocer, firmado por el Arquitecto Mayor del Rey y Maestro Mayor de la Villa de Madrid, Juan Gómez de Mora, fue destinado a una vivienda propiedad del Conde de Barajas en la Caba de San Miguel de Madrid (Fig. 5) (Documento). Es una obra en la que se plantea adecuar la disposición de la nueva vivienda al moderno equipamiento técnico de las casas, casi colindantes, configuradas en la Plaza Mayor, obra esta en su conjunto que habla sido creada en 1617 por el mismo arquitecto ${ }^{1}$. El proyecto para el Conde de Barajas responde a una casa "tipo», cuya sección, iluminación, ventilación, llenos y vacíos, etc., funcionan como planteamiento para el logro de un organismo simple pero unitario, y cuya unidad y simplicidad geométrica fue convertida por Juan Gómez de Mora a través de su amplia aportación arquitectónica doméstica, en "consigna", en signo y símbolo de la arquitectura española. En el siglo XVII estas ideas dieron lugar sin duda a una nueva tipología de habitación. La unidad como principio debe regir el «todo» a pesar de que el conjunto deba partir de elementos hetereogéneos, siempre sustentados por componentes elementales y rigurosamente disciplinados. Ninguno de los arquitectos de la primera mitad del siglo xvir tuvo ocasión de construir tantas obras como las que se confiaron a Juan Gómez de Mora. Sin embargo el volumen de sus intervenciones no fue un freno ni un impedimento para poner a prueba la creatividad de este consumado maestro. En su aportación a la arquitectura española del siglo xvII el tema doméstico ocupa en su obra también un lugar relevante, tanto en cuestiones de uso, de espacio, u ornamernto. Las aplicaciones de una trama regular al fachadismo de la capital, el énfasis dado al ladrillo visto, el lenguaje de la línea recta y del plano liso, el balcón en voladizo, la reafirmación de la línea horizontal, la ventana

\footnotetext{
1 Este diseño refleja la composición de los frentes porticados de la Plaza Mayor de Madrid en su primitiva configuración ya que fue dibujado por el autor de la propia Plaza Mayor, el arquitecto del Rey Felipe IV Juan Gómez de Mora, antes del incendio de 1631. Nos parece un importante testimonio de su organización a nivel de sus cuatro cuerpos y ático, su balconaje y la composición de pórtico de piedra y superficies de ladrillo visto.

2 V. Tovar Martín. Juan Gómez de Mora (1586-1648) Catálogo Exposición. Madrid, 1986. A. Bonet Correa: El plano de Juan Gómez de Mora de la Plaza Mayor de Madrid de 1636. Anales del Instituto de Estudios Madrileños, tomo IX, 1973, pp. 15-53. A. Bonet Correa: Morfología y Ciudad. Urbanismo y Arquitectura durante el antiguo Régimen en España. Barcelona, 1978 .
} 

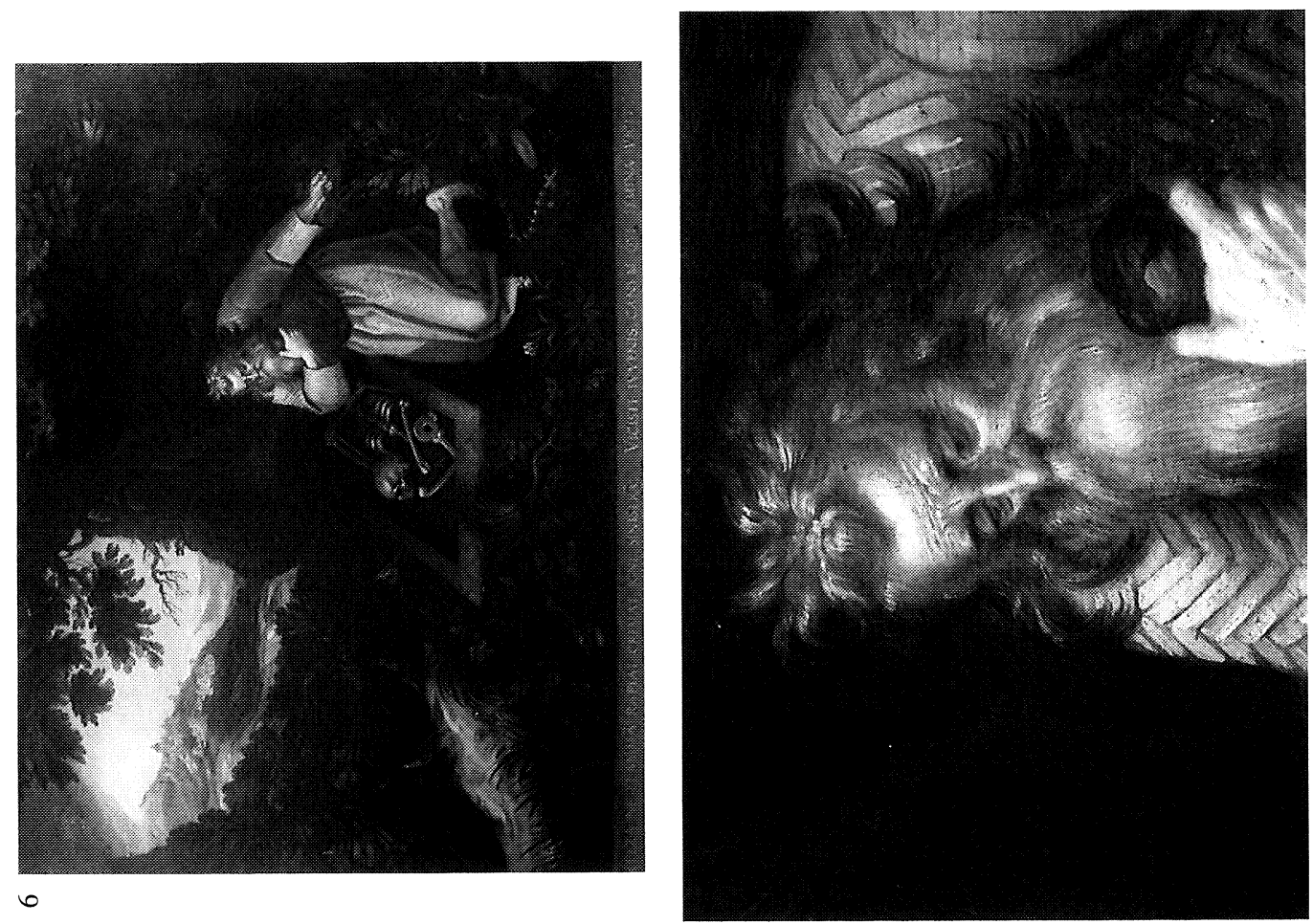

6

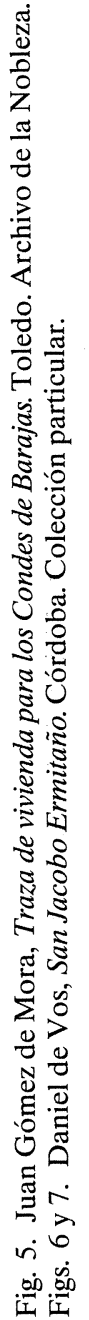
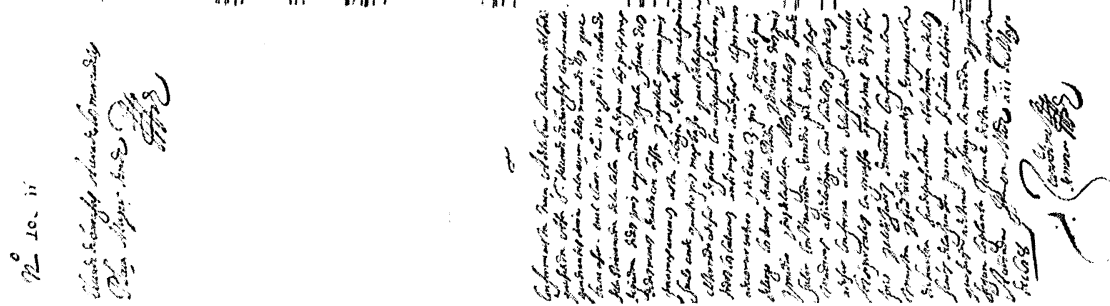
trazada sobre el muro como ideograma arquitectónico, o la línea recta implacable y deliberadamente dibujada como medio conductor, son algunas de las fórmulas utilizadas y reafirmadas conceptualmente por Juan Gómez de Mora en su búsqueda de una arquitectura de articulación clara, de trama geométrica precisa cuya clave artística siempre se asocia a la idea de disciplina formal.

El proyecto que hoy añadimos a su ya extenso catálogo viene a confirmar una vez más la coherencia estilística que le caracteriza; y lejos de cualquier beligerancia, Juan Gómez de Mora confirma en esta obra una vez más su serio y riguroso sentido de la experimentación arquitectónica pragmática. El efecto plástico de la casa de los Condes de Barajas en el dibujo de Juan Gómez de Mora subraya el valor de la sencillez, de la belleza del material sin desnaturalizar su sustancia y también la significativa prestancia de la superficie desnuda. En el tema de la arquitectura ciudadana plurifamiliar, este arquitecto supo dar un importante salto cualitativo con obras en las que se saturan en armonioso juego materiales sencillos y elementos geométricos escuetos.

CRistóbal Marín Tovar

Documento de la Nobleza. Colec. Fernán Núñez Legajo 1619/24

Dibujo a tinta gris, negra y roja. Firmado y rubricado Juan Gómez de Mora. Nota manuscrita «Conforme a esta traza sea de labrar la delantera del sitio que se da a S. Exm el conde de Barajas conforme a lo que de antes había en la acera de los mercaderes que viene a ser en el claro número 10 y número 11 contando de la rinconada de la cava anse de poner las pilastras de piedra de dos pies en quadrado y por la frente dos dedos menos de alto con bassa y capitel quinze pies poco mas o menos asta la biga de frente que el primer suelo ande quatro pies mas bajo que el de la Panaderia el terrado a de ser de plomo con antepechos de hierro todos los balcones asi mismo lo an de ser el primero a de ser entero y de vuelo 3 pies y de nueve pies de largo los demas de alli arriba y de buelo dos pies y medio y desde laplaza a los soportales se ha de salir con una grada de de medio pie de alto y las maderas asi de la biga como las de los soportales a de ser conforme al auto de la junta y de ancho los soportales con grueso de pilastras dieciseis pies y el tijaroz de madera conforme a la muestra y se advierte que antes de empezarla dicha obra se ha de presentar esta traza ante los Señores de la Junta para que se señale el sitio quer su Excelencia a de tener y se aga la medida y quenta segun la planta general de esta obra questa acordada. En Madrid a 11 de mayo de 1628. Juan Gomez de de Mora.»En el ángulo superior "En Conde de Barajas Acera de los Mercaderes. Plaza Mayor de Madrid» Rubricado por el mismo arquitecto.

\section{UN CUADRO INEDITO DE DANIEL DE VOS EN ESPAÑA}

La presencia de pintura flamenca en España no ha constituido nunca una novedad, salvo cuando se trata de la obra de un artista poco conocido o escasamente representado en nuestro país. Este es el caso de Daniel de Vos (1568-1605), un pintor del que apenas si conocemos algún dato aparte de su formación en el taller de su padre, Martín de Vos (1532-1603), y su ingreso en las Guildas de Flandes ${ }^{1}$.

1 El conocimiento actual de la vida y obras de Daniel de Vos es tan escaso que sólo encontramos breves referencias a él en los grandes diccionarios de arte. Así el reciente The Dictionary of Art editado por Jane Turner (MacMillan, Londres, 1996, vol. 32, p. 709) sólo incluye una breve mención dentro de la voz referida a su padre: «In his second will of 10 October 1603, de Vos bequeathed his painting equipment, drawings and the like to his sons Daniel de Vos (1568-1605) and Marten de Vos the younger (1576- 1613).» Obras anteriores como la de E. Benezit, Dictionnaire des Peintres, Sculpteurs, Dessinateurs et Graveurs (Librairie Gründ, París, 1966, vol. 8, p. 623), son igualmente escuetas: «Peintre, baptisé à Anvers le 25 mai 1568 , mort en 1605 (Ec. Flam.). Fils de Marten de V. "; o, como U. Thieme-Becker, Allgemeines lexikon der Bildenden Künstler (Seeman, Leipzig, 1976-1983, vol. XXXIV, pp. 553 y 555), apenas si lo mencionan como hijo de Martín de Vos.

En lo que se refiere a la presencia de su obra en España, tenemos que agradecer a don Matías Díaz Padrón la noticia de la existencia de varios cuadros de Daniel de Vos en nuestro país, que permanecen inéditos aún; sin que conozcamos que se haya publicado en España alguna otra obra del pintor flamenco. 